\title{
AVALIAÇĀO DA SATISFAÇÃO DE USUÁRIOS DE MORADIAS POPULARES EM LOTEAMENTOS DE INTERESSE SOCIAL NO RIO GRANDE DO SUL
}

\author{
MYLENA LANUSSI ROSSI BIRCK \\ Engenheira Civil \\ LEME/UFRGS \\ RS; Brasil \\ mylenabirck@gmail.com
}

\author{
MORGANE BIGOLIN \\ Arquiteta \\ LEME/UFRGS \\ RS; Brasil \\ morgane.b@gmail.com
}

\author{
ALEXANDRE LORENZI \\ Engenheiro Civil \\ LEME/UFRGS \\ RS; Brasil \\ alexandre.lorenzi@ufrgs.br
}

\author{
LUCIANI SOMENSI LORENZI \\ Engenheira Civil \\ LEME/UFRGS \\ RS; Brasil \\ luciani.lorenzi@gmail.com
}

\author{
LUIZ CARLOS PINTO DA SILVA FILHO \\ Engenheiro Civil \\ LEME/UFRGS \\ RS; Brasil \\ lcarlos66@gmail.com
}

\begin{abstract}
RESUMO
$\mathrm{O}$ acesso a uma habitação que atenda às necessidades mínimas de habitabilidade, segurança e durabilidade, mostram-se quesitos fundamentais na busca por uma moradia própria. A maioria da população que busca estas características vive, na maioria dos casos, em situações precárias e sem condições de infraestrutura básica. O trabalho teve como objetivo efetuar uma Avaliação Pós-Ocupação das casas produzidas pelo Departamento de Habitação da Prefeitura de Porto Algre (DEMHAB). Esta avaliação fundamenta-se na perspectiva e satisfação do usuário, além de identificação e levantamento das manifestações patológicas mais recorrentes nestes loteamentos, resultando em um diagnóstico da performance e evolução das HIS. Esta pesquisa foi desenvolvida partir da aplicação de um questionário em uma amostra de moradores destes empreendimentos, apontando seu nível de satisfação com o imóvel. Considerando os resultados da pesquisa, os relatos dos usuários apontam para um nível de satisfação "regular" perante a suas habitações. A insatisfação dos usuários evidencia-se quando $88,61 \%$ dos entrevistados declarou já ter realizado ou deseja realizar reformas na sua moradia, sendo a mais frequente a ampliação da moradia. $\mathrm{O}$ trabalho intenciona servir de base para projetos futuros do DEMHAB, a fim de que as próximas HIS atendam às necessidades e expectativas dos usuários. Além de fundamentar estratégias de manutenção e correção das manifestações patológicas apontadas nesta tipologia de habitações.

Palavras-chave: MCMV, habitação de interesse social, manifestações patológicas.
\end{abstract}

\section{ABSTRACT}

Finding a housing that meets the basic requirements of habitability, safety and durability, are fundamental in the acquisition of a new home. The population aiming these characteristics live, in most cases, in precarious settlements and without basic infrastructure conditions. This work aim to apply a Post-occupation Assessment of the houses produced by Porto Alegre municipality (DEMHAB). This assessment was based on the perspective and user satisfaction, additionally to the identification and inspection of the most recurrent pathological manifestations in these houses, resulting in a performance diagnosis of the social interest housing. This research was developed through the application of a questionnaire to a sample of residents, aiming to investigate their level of satisfaction with the property. Considering the survey results, residents' reports point to a "regular" level of satisfaction with their homes. The dissatisfaction of users is evident when $88.61 \%$ of respondents stated that they have already carried out or want to carry out renovations in their housing, being the most frequent the expansion of the housing unit. The work aimed to underpin future projects in order to meets resident's requirements and expectations. In addition, this work address strategies for maintenance and recovery of the most frequent pathological manifestations observed in this housing types.

Keywords: My house my life programme, affordable housing, building pathological manifestations. 


\section{INTRODUÇÃO}

A inadequada distribuição de renda somado ao elevado crescimento populacional urbano resultou em um complexo déficit habitacional no Brasil. Nas metrópoles foram aumentando o número de assentamentos precários e irregulares, carentes de infraestrutura, acessibilidade, saneamento, acesso a recursos básicos, importantes para uma vida digna. Identificando o déficit habitacional como um problema de gestão pública, instituições e órgãos públicos investiram em políticas habitacionais, por meio de programas e ações que, de diferentes maneiras, oportunizaram acesso a moradia a pessoas com baixa renda. Entretanto, a necessidade de baixo custo e produção em quantidade das Habitações de Interesse Social (HIS), levam ao emprego de processos construtivos e soluções que, muitas vezes, negligenciam a qualidade deste produto e a real necessidade do usuário.

Torna-se, então, necessário realizar diagnósticos de desempenho e evolução das moradias existentes em empreendimentos de HIS, observando questões relativas à qualidade da habitação, satisfação do usuário e processos patológicos. Um método de análise do desempenho e qualidade do ambiente construído é a Avaliação Pós-Ocupação (APO), através do ponto de vista do usuário, permite avaliar não somente aspectos técnicos, mas também comportamentais e sociais, proporcionando a compreensão e registro da realidade existente. Estes dados, tornam-se diretrizes para novos projetos e orientações para possíveis soluções de recuperação destas habitações.

Apesar da acelerada construção de HIS no país, ainda são atípicas as pesquisas que visam avaliar de forma estruturada a performance pós-uso e a durabilidade dessas habitações. Ainda mais raras são as pesquisas relativas a este assunto no Rio Grande do Sul. Tendo em vista que o poder público se propõe a produzir HIS em grande quantidade e com baixo custo, se faz necessário um sistema de avaliação constante. Portanto, esta pesquisa se justifica ao efetuar um diagnóstico da performance e evolução das moradias de empreendimentos de HIS produzidas pelo poder público de Porto Alegre, atentando a questões relativas à qualidade da habitação, satisfação do usuário e processos patológicos. Assim, este artigo, propõe-se a avaliar HIS dos loteamentos Chapéu do Sol, São Guilherme e Nova Chocolatão em Porto Alegre, RS. Reunindo resultados de questionários aplicados aos moradores e relatórios fotográficos, almeja-se identificar as carências e manifestações patológicas, além de avaliar o desempenho e a qualidade das unidades habitacionais, embasando-se no ponto de vista do usuário e seu nível de satisfação.

A abordagem estruturada do assunto permitiu o entendimento da realidade dos conjuntos habitacionais de Porto Alegre, orientando a definição das medidas necessárias, permitindo a geração de indicadores para novos projetos, e proporcionando a sistematização e transmissão à população de possíveis soluções de recuperação. Este trabalho de pesquisa foi viabilizado e realizado em parceria com o Departamento Municipal de Habitação de Porto Alegre e com a Rede Morar TS da Financiadora de Inovação e Pesquisa - Finep -, uma rede nacional de diversas Centros Acadêmicos no País, voltada para desenvolvimento de pesquisas e tecnologias sobre moradia, com foco em tecnologias socias que representem efetivas soluções para problemas sociais, levando à transformação de um contexto social. Este trabalho, especialmente, integra o Subprojeto 5 - Desempenho e pós-uso das edificações.

\section{REVISÃO BIBLIOGRÁFICA}

Abiko (1995) afirmou que a habitação tem como função principal, abrigar e proteger o ser humano. Através da evolução humana, o homem foi descobrindo e desenvolvendo habilidades e aptidões, passando a utilizar os materiais disponíveis como ferramentas para incrementar seus abrigos. Ao longo da história, adquiriu também uma função econômica e social, sendo local de descanso, alimentação, atividades fisiológicas e convívio social. Portanto, a habitação é uma necessidade básica do ser humano.

Entretanto, nos dias atauais, a questão habitacional sobressai de um complexo problema socioeconômico. As carências habitacionais não se limitam tão somente a falta de moradia, mas está articulada ao contexto social, econômico e cultural e políticos. O déficit habitacional não será resolvido com políticas para produção de moradias sem investir conjuntamente em qualidade, infraestrutura e coletividade, enfatiza Maricato (2000).

Em 2015, segundo a Pesquisa Nacional por Amostra de Domicílios do IBGE, o Brasil possuía 6.355.743 moradias em condições precárias. O Rio Grande do Sul registrou um déficit de 239.458 moradias em 2015. A Região Metropolitana de Porto Alegre-RMPA registrou, em 2015, um déficit de 96.614 moradias, sendo $98 \%$ na zona urbana. Segundo a Síntese de Indicadores Sociais do IBGE (2018), em 2017, 13,0\% da população brasileira residia em domicílios inadequados, o que representa 27 milhões de pessoas e 7,8 milhões de domicílios. 


\subsection{Habitação de Interesse Social}

Habitação de Interesse Social (HIS) é definida por Bonduki (1994). como habitação voltada a atender a parcela da população com renda baixa. Santos $(2011$, p. 3) traz um conceito mais recente ao enfatizar que a HIS não é apenas uma construção para baixa renda, ou seja, um produto. O seu projeto deve empregar técnicas e processos que diminuam o custo, sem diminuir a qualidade e que supram todas as necessidades de seus domiciliados.

Diversos conceitos devem ser observados quando se trata de Habitação de Interesse Social, não se limitando apenas ao produto material da edificação. Abiko (1995, p. 12) reforça que a HIS é o resultado de um processo complexo com determinantes políticos, sociais, econômicos, jurídicos, ecológicos, tecnológicos; que são fundamentais para solução do problema habitacional. Como elucidado na figura 1, para a Rede Morar TS, Habitações de Interesse Social devem resultar da interação e combinação de cidadania, sustentabilidade, integração com a cidade, habitabilidade, racionalidade produtiva e integração com Políticas Públicas (CARDOSO; KAPP, 2013).

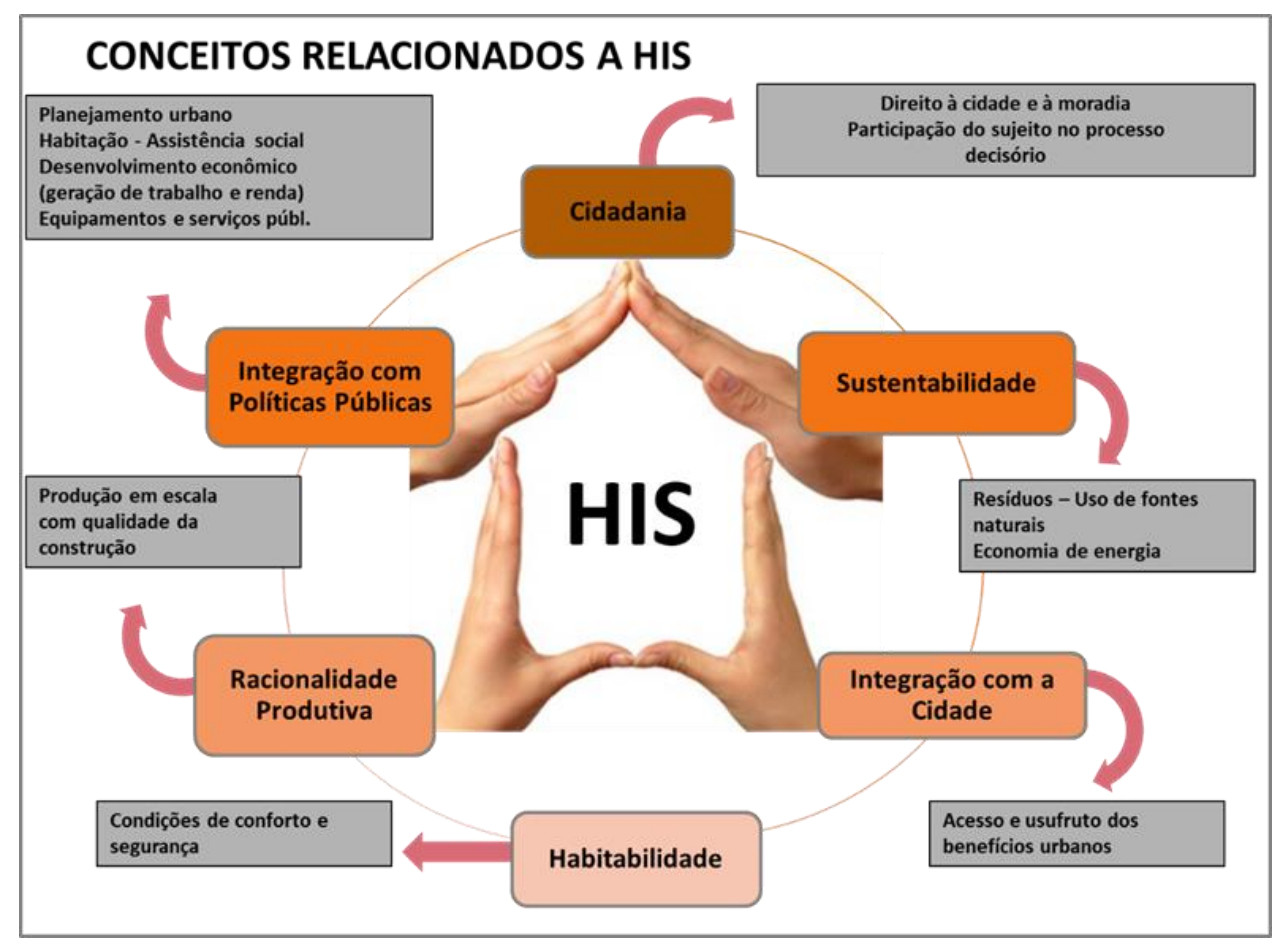

Figura 1: Conceitos relacionados à Habitação de Interesse Social

\section{METODOLOGIA}

A Avaliação Pós-ocupação (APO) é um método de que mensura o desempenho de ambientes construídos com base nas percepções dos usuários e no relacionamento usuário-ambiente. As primeiras pesquisas nesta área surgiram em 1947 nos Estados Unidos, como parte dos estudos dos psicólogos Roger Barkes e Herbert Wright que avaliavam a interação entre o ambiente e o comportamento dos indivíduos (ORNSTEIN, 1992). No Brasil, o despertar da APO ocorreu em 1975 com a pesquisa de Motta Del Carlo sobre os níveis de satisfação dos moradores de conjuntos habitacionais da Grande São Paulo (ORNSTEIN, 1992).

França (2016) enfatiza a singularidade da APO: avalia o desempenho de forma efetiva e integrada, já que ela prioriza aspectos de uso, manutenção, considerando essencial o ponto de vista dos usuários e não somente atributos técnicos. Para sua realização várias técnicas podem ser empregadas como Rheingatz (2008) complementa Ornstein (2004) destacando as principais: Walkthrough, Mapa comportamental, Poema dos desejos; dMapeamento visual; Mapa mental; Seleção visual; Entrevista; Questionário e Grupo Focal. 
O método escolhido para este trabalho foi de entrevista. O roteiro de questionário foi elaborado pelos pesquisadores da Rede Morar TS da UFRGS, Universidade de São Paulo, Universidade de Campina Grande e FIOCRUZ. Definiu-se que o questionário seria na forma de entrevista e não auto aplicado, tendo em vista a possibilidade de interação entre o pesquisador e o respondente, de modo que as questões pudessem ser esclarecidas, em caso de dúvida, e, assim, as respostas registradas. Adotou-se o método de escala de valor para as respostas, procurando usar números e símbolos que facilitassem o entendimento do público alvo.

O questionário foi constituído por 37 questões, distribuídas em 6 blocos, iniciando com uma contextualização, depois caracterização do ambiente e seu uso e por fim patologias:

a) Dados Gerais da moradia atual;

b) Dados Gerais da moradia anterior;

c) Perfil do agrupamento familiar;

d) Caracterização da Edificação e seus ambientes;

e) Quanto ao modo de utilização da moradia; e

f) Caracterização das manifestações patológicas.

Os questionários foram aplicados de 2012 a 2014. Os entrevistados tiveram suas dúvidas esclarecidas e assinaram um termo de consentimento livre e esclarecido, registrando seu interesse em participar de forma voluntária nesta pesquisa.

Seguido das entrevistas, também foi realizada uma análise do ponto de vista técnico. A avaliação técnica foi realizada baseando-se em visitas técnicas executadas por Engenheiros Civis, pesquisadores da Rede Morar TS, que aplicaram os questionários e entrevistaram os usuários. Nesta visita, os pesquisadores apontaram as ocorrências que identificaram, complementando com registros fotográficos.

\subsection{Definição da Amostra}

A seleção da amostra dos domicílios foi realizada baseando-se no processo de amostragem aleatória simples, portanto, todas as Unidades Habitacionais - UH - tinham igual probabilidade de pertencer à amostra, respeitando-se a disponibilidade dos usuários no momento das entrevistas. Além disso, para evitar conclusões tendenciosas, contemplouse de forma igual todas as orientações geográficas das fachadas frontais das unidades, tendo em vista que esta pode causar diferenciação na captação de luz natural e ventilação na definição das residências. As unidades da amostra foram definidas pelo líder comunitário de cada empreendimento em conjunto com a Coordenadora de Projetos do DEMHAB e os pesquisadores da Rede Morar TS.

No loteamento Chapéu do sol, aplicou-se o questionário em $40 \mathrm{UH}$, representando 6,94\% das UH ocupadas deste loteamento. As unidades selecionadas foram todas da mesma tipologia casa térrea. Neste empreendimento a amostra foi reduzida por orientação da Líder Comunitária e devido a questões de segurança alguns pontos do loteamento foram descartados da amostragem. No loteamento São Guilherme, os questionários foram aplicados em 26 UH, representando $10,32 \%$ das UH do loteamento, nas diferentes tipologias. No Residencial Nova Chocolatão, os questionários foram aplicados em $25 \mathrm{UH}$, representando 13,81\% das UH do loteamento, nas diferentes tipologias.

\subsection{Análise dos dados}

A Análise dos dados foi realizada através de gráficos, planilhas e tabelas, por meio do software Microsoft Excel. As respostas foram classificadas como "Ruim" as quais receberam valor 1, "Regular" valor 2, "Bom" valor 3 e "Ótimo" valor 4 .

O Índice de Satisfação Médio foi calculado ponderando as respostas, ou seja, multiplicou-se o valor atribuído (de 1 a 4 ) pela porcentagem de respostas do nível, a soma disto resulta no Índice de Satisfação Médio do loteamento. Tratando-se da média geral de todos os empreendimentos, considerou-se a média simples aritmética dos Índices de Satisfação individuais dos loteamentos. Considerou-se insatisfeitos os usuários que avaliaram entre "regular" e "ruim" e satisfeitos os que avaliaram entre "bom" e "ótimo". 


\section{RESULTADOS}

A grande maioria dos entrevistados eram os primeiros moradores da unidade, estando nelas desde sua entrega. No Loteamento Chapéu do Sol, isso representa de 12 a 13 anos. No Residencial Nova Chocolatão, 2 anos, e no Loteamento São Guilherme, moradores da primeira fase 8 anos e moradores da segunda fase, menos de 1 ano. A respeito do número de morados por residência, a média de moradores em todos os loteamentos é aproximadamente 4 pessoas, variando de 1 a 17, no caso do Residencial Nova Chocolatão, 1 a 8, no caso do Loteamento Chapéu do Sol e 2 a 7 no caso do Loteamento São Guilherme.

A tabela 1 expressa a quantidade de entrevistados que permitiram que esta visita fosse realizada, repercutindo na redução da amostra.

Tabela 1 - Quantidade de entrevistados que permitiram a visita técnica e/ou os registros fotográficos em suas moradias

\begin{tabular}{c|c|c|c}
\hline & Chapéu do Sol & Nova Chocolatão & São Guilherme \\
\hline Amostra & 40 & 25 & 26 \\
\hline Vistoria Tecnica & 24 & 18 & 19 \\
\hline Fotografar & 25 & 17 & 19 \\
\hline
\end{tabular}

Foram identificadas, catalogadas e fotografadas as ocorrências de manifestações patológicas. A proporção de unidades com defeitos registrados é similar entre os loteamentos, variando entre $72,22 \%$ no Residencial Nova Chocolatão e $75 \%$ no Loteamento Chapéu do Sol, em geral 73,77\% das unidades visitadas teve algum defeito registrado. Observa-se que o loteamento Chapéu do Sol apresentou uma média de ocorrências (13,67/uh) muito maior que os demais, elevando a média geral para 8 ocorrências por unidade, foi neste loteamento, também, que $67,21 \%$ das ocorrências foram apontadas.

O levantamento dos defeitos foi realizado dividindo os apontamentos que se supunha serem mais frequentes entre 10 grupos de elementos: fundações, piso, paredes, revestimento, pintura, portas e janelas, cobertura, instalação hidráulica, instalação esgoto e instalação elétrica. Foi verificado a presença de defeitos, anotando observações e registrando por meio de fotografias.

\subsection{Fundações}

Como defeito de fundação foram considerados umidade, fissuras e movimentação de elementos da construção. Observa-se que no Loteamento Chapéu do Sol, $45,85 \%$ das unidades visitadas apresentou algum tipo de defeito nas fundações, o mais recorrente foi umidade $(45,83 \%$ das UH). Já no Loteamento São Guilherme, 10,53\% das unidades apresentavam defeito neste elemento. No Residencial Nova Chocolatão nenhuma unidade apresentou defeito nas fundações.

De maneira geral $21,31 \%$ das unidades vistoriadas apresentou problema nas fundações. Ressalta-se que $90 \%$ dos 30 casos foram identificados no Loteamento Chapéu do Sol. Como mostra a figura 1, 40\% dos defeitos nas fundações foram identificados como umidade. A figura 2 ilustra o problema de umidade nas fundações.

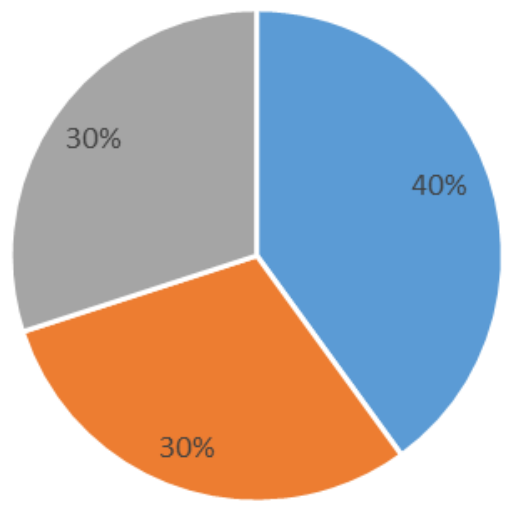

Figura 1: Distribuição das ocorrências em fundações 


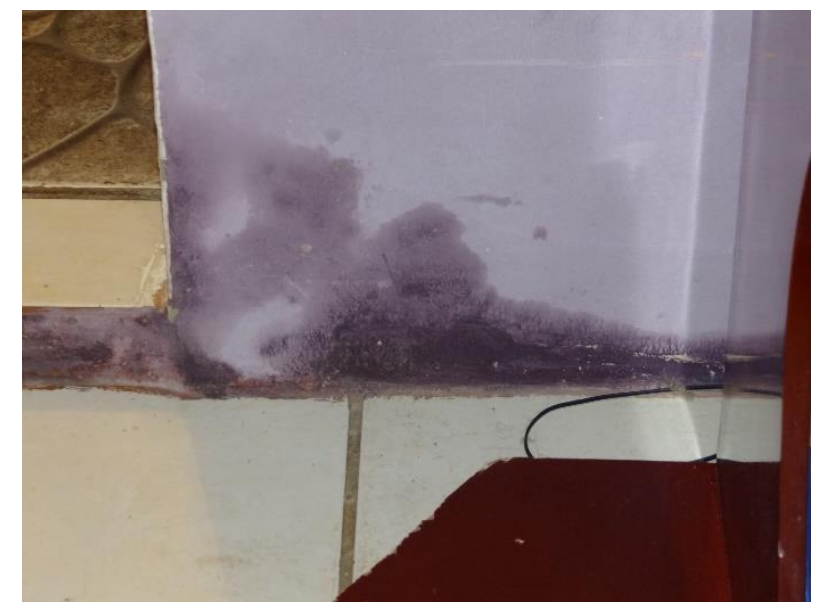

Figura 2: Umidade proveniente das fundações no Loteamento. Chapéu do Sol

\subsection{Piso}

Como defeito no piso foram considerados umidade, fissuras, esfarelamento ou outros. No Loteamento Chapéu do Sol $62,50 \%$ das unidades apresentou defeitos no piso, sendo o mais recorrente a umidade (presente em 50\% das UH). Em Nova Chocolatão $27,78 \%$ das unidades acusou defeito no piso. No Loteamento São Guilherme, $26,32 \%$ das unidades apresentou defeitos no piso, sendo o defeito mais frequente umidade, que foi apontado em $21,05 \%$ das unidades vistoriadas.

De maneira geral $40,98 \%$ das unidades vistoriadas apresentou problema nos pisos. Ressalta-se que $75,6 \%$ dos 45 casos foram identificados no Loteamento Chapéu do Sol. Como mostra a figura 70, 38\% dos defeitos nos pisos foram identificados como umidade. A figura 4 ilustra o problema de pisos soltos, acompanhado de umidade.

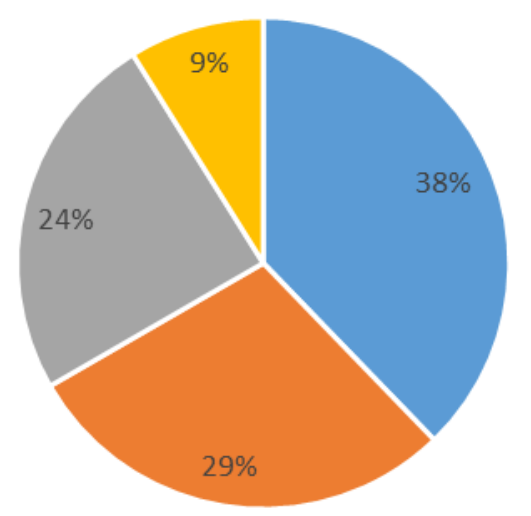

$$
\begin{aligned}
& \text { - Umidade } \\
& \text { - Fissuras } \\
& \text { - Esfarelando } \\
& \text { - Outro }
\end{aligned}
$$

Figura 3: Distribuição das ocorrências em pisos

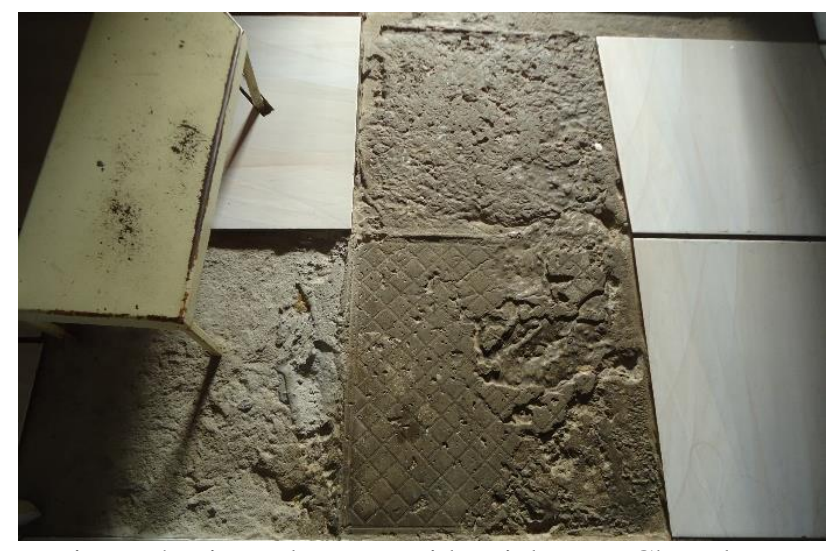

Figura 4: Piso solto no Residencial Nova Chocolatão 


\subsection{Paredes}

Como defeito de paredes foram considerados umidade, fissuras, manchas de bolor e outros. A tabela 13 apresenta os resultados a respeito do elemento Parede. No Loteamento Chapéu do Sol, 70,83\% das unidades visitadas apontou defeito nas paredes, o mais recorrente foi umidade $(70,83 \%$ das UH), seguido de fissuras (54,17\% das unidades). Já no Loteamento São Guilherme, $52,63 \%$ das unidades apontaram defeito neste elemento, sendo o defeito mais frequente umidade $(42,11 \%$ das unidades). No Residencial Nova Chocolatão 38,89\% das unidades manifestou defeito nas paredes.

Globalmente, 55,74\% das unidades vistoriadas apresentou problema nas paredes. Ressalta-se que $67,7 \%$ dos 65 casos foram identificados no Loteamento Chapéu do Sol. Como mostra a figura 5, 40\% dos defeitos nas paredes foram identificados como umidade, muitas vezes acompanho de manchas de bolor, presente em 21\% das unidades. Em 34\% das unidades foram identificadas fissuras nas paredes.

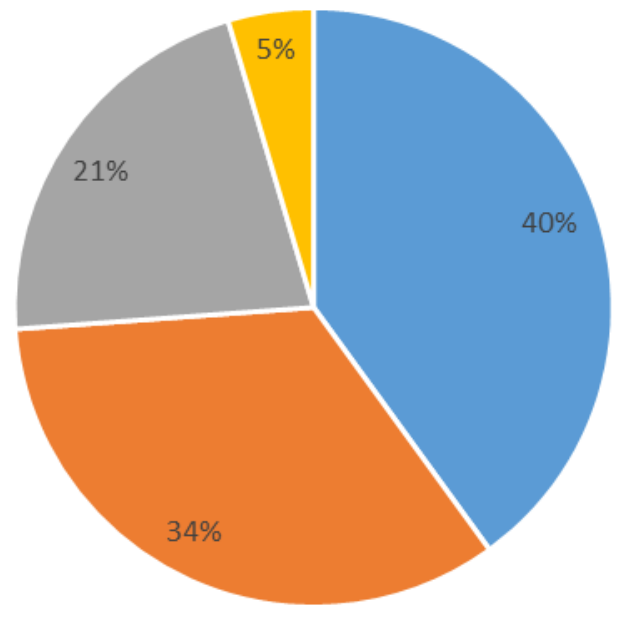

$$
\begin{aligned}
& \text { - Umidade } \\
& \text { - Fissuras } \\
& \text { - Manchas de bolor } \\
& \text { - Outro }
\end{aligned}
$$

Figura 5: Distribuição das ocorrências em paredes

A figura 6 ilustra o problema de umidade nas paredes, que tem relação com o problema das manchas de bolor.
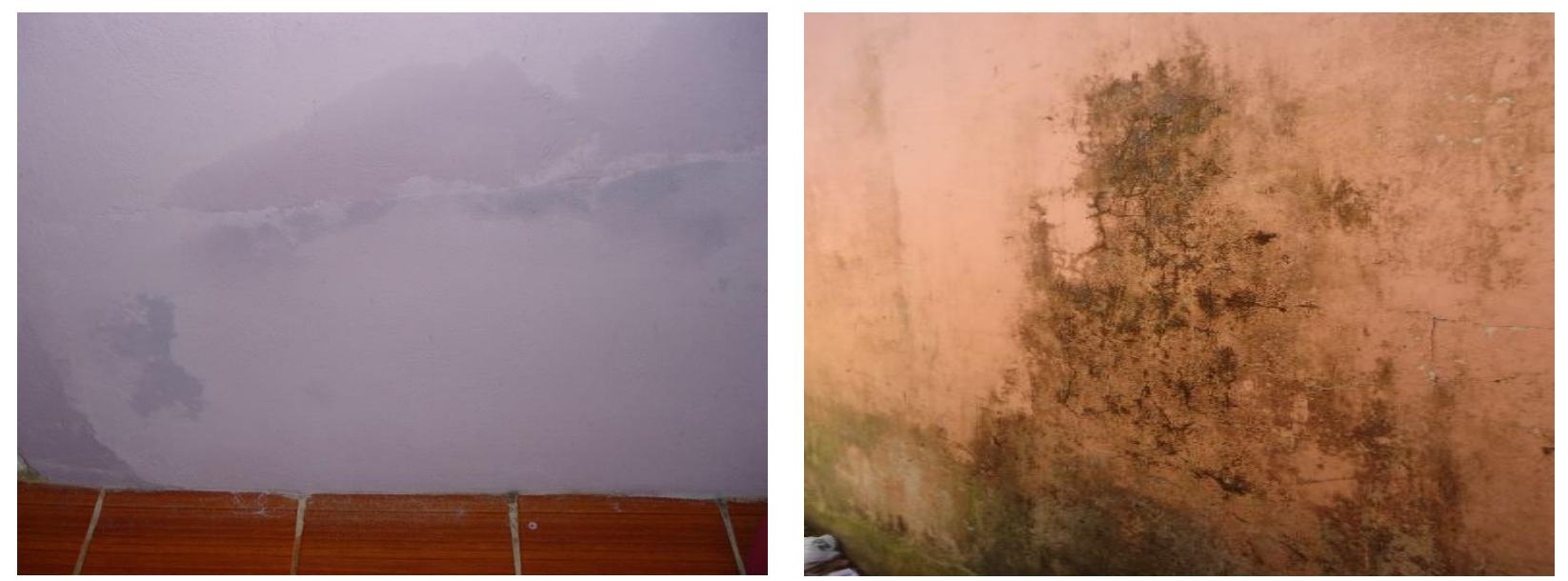

Figura 6: Parede com presença de umidade no Loteamento Chapéu do Sol

Um problema recorrente em todos os loteamentos é a ocorrência de fissuras no entorno das esquadrias (portas e janelas), conforme ilustrado na Figura 7. 


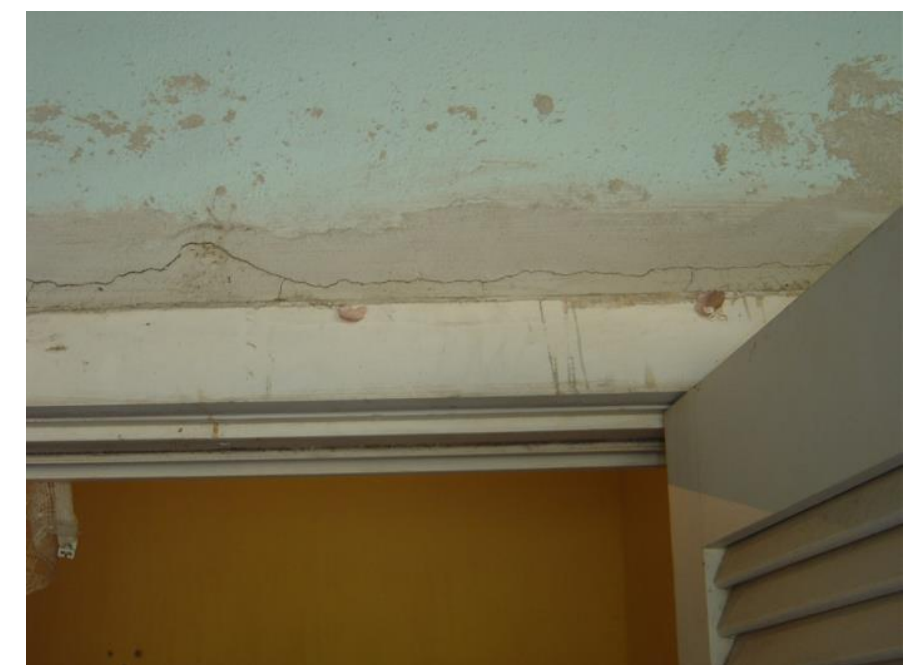

Figura 7: Parede com fissuras no entorno da janela no Loteamento Chapéu do Sol

\title{
4.4 Revestimentos
}

Como defeito no revestimento foram considerados estufamento, partes soltas, esfarelamento e outros. No Loteamento Chapéu do Sol, 33,33\% das unidades visitadas manifestou defeitos no revestimento, atenta-se que foram identificados estufamento, revestimento solto e esfarelado em todas estas unidades. Já no Loteamento São Guilherme, 31,58\% das unidades apontaram defeito neste elemento, sendo o defeito mais frequente revestimento solto ( $21,05 \%$ das unidades). No Residencial Nova Chocolatão 16,67\% das unidades manifestou defeito nas no revestimento, sendo identificados apenas estufamento.

Globalmente, 27,87\% das unidades vistoriadas apresentou problema nos revestimentos. Ressalta-se que 68,6\% dos 35 casos foram identificados no Loteamento Chapéu do Sol. Como mostra a figura 99, $40 \%$ dos defeitos de revestimento foram identificados como estufamento, apontado em $22,95 \%$ das unidades, outros $34 \%$ foram identificados como esfarelamento, presente em $19,67 \%$ das unidades.

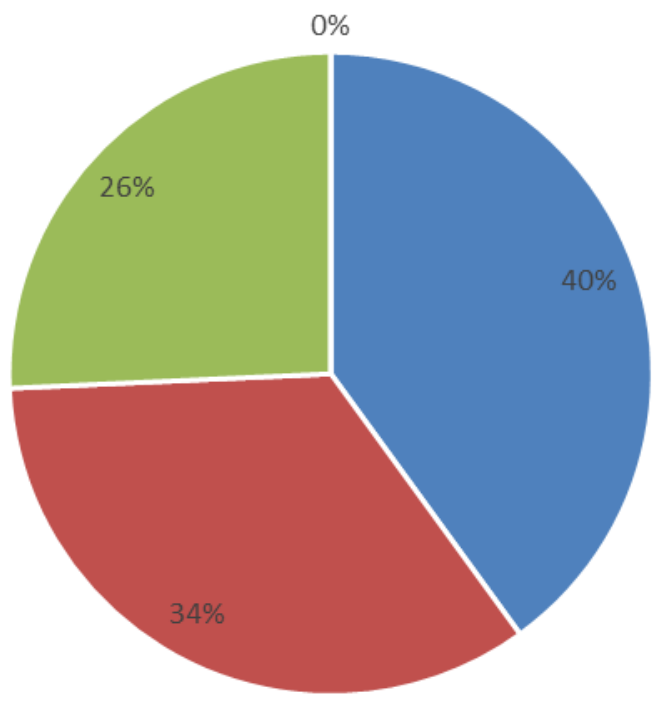

\author{
- Estufado (com bolhas) \\ - Solto \\ - Esfarelando \\ - Outro
}

Figura 8: Distribuição das ocorrências em revestimentos

No loteamento Chapéu do Sol as unidades foram entregues sem acabamentos, algumas ainda continuam sem. Devido à falta de manutenção, algumas unidades estão com o revestimento totalmente degradado. Uma ocorrência bastante frequente, também motivo de insatisfação dos entrevistados, é o desplacamento cerâmico.

Um ponto com bastante ocorrências de desplacamento é no entorno das esquadrias (portas e janelas), processo iniciado por fissuramento, depois esfarelamento e por fim, desplacamento do revestimento, como ilustrado pela figura 9. 


\section{CBPAT 2020 \\ concersso ans \\ DE 15 A 17 DE ABRIL | FORTALEZA - CE}

ISBN 978-65-86819-05-2

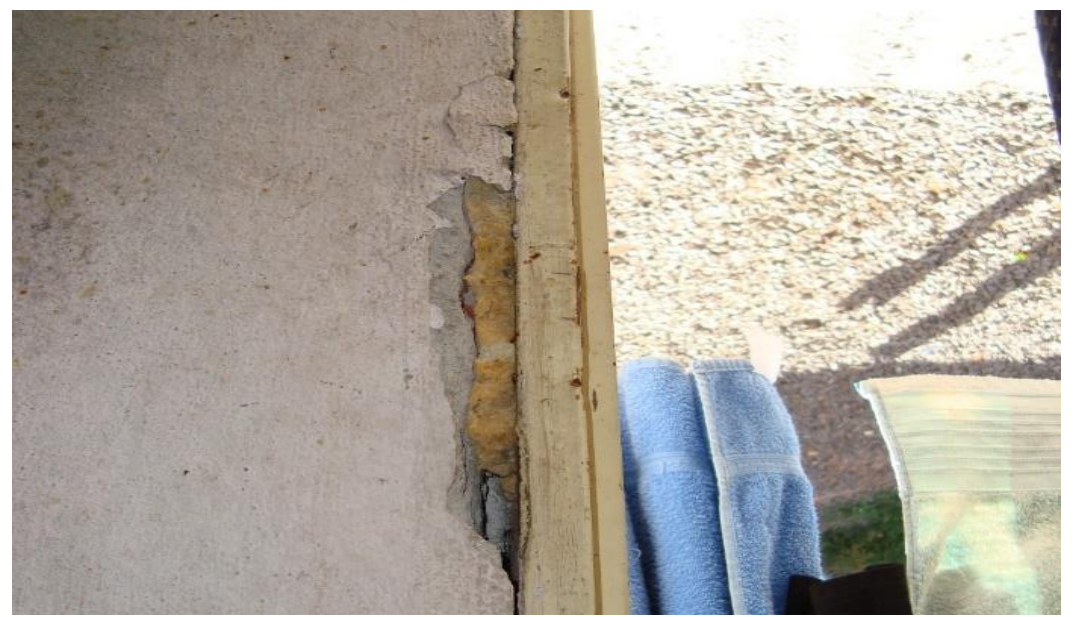

Figura 9: Revestimento esfarelado e desplacado no ponto de fixação da porta no Loteamento Chapéu do Sol

\subsection{Pinturas}

Como defeito de pintura foram considerados presença de bolhas, descascamento, desbotamento, manchas e outros. No Loteamento Chapéu do Sol, 54,17\% das unidades visitadas manifestou defeitos na pintura, sendo que $50 \%$ das unidades estavam com a pintura descascada em algum ponto e $47,83 \%$ a pintura estava manchada. Enquanto no Residencial Nova Chocolatão, 44,44\% apontaram defeitos na pintura, sendo que 33,33\% estavam com a pintura manchada. No Loteamento São Guilherme $42,11 \%$ das unidades manifestou defeitos na pintura, manchas e descascamento ocorreram em $21,05 \%$ das unidades.

Integralmente, $47,54 \%$ das unidades vistoriadas apresentou problema na pintura. Destaca-se que 58,60\% dos 70 casos foram identificados no Loteamento Chapéu do Sol, com uma média de 1,71 casos por unidade. Como mostra a figura 111, manchas e descascamento representaram $60 \%$ das ocorrências em pintura, sendo apontadas individualmente em $34,43 \%$ das unidades visitadas.

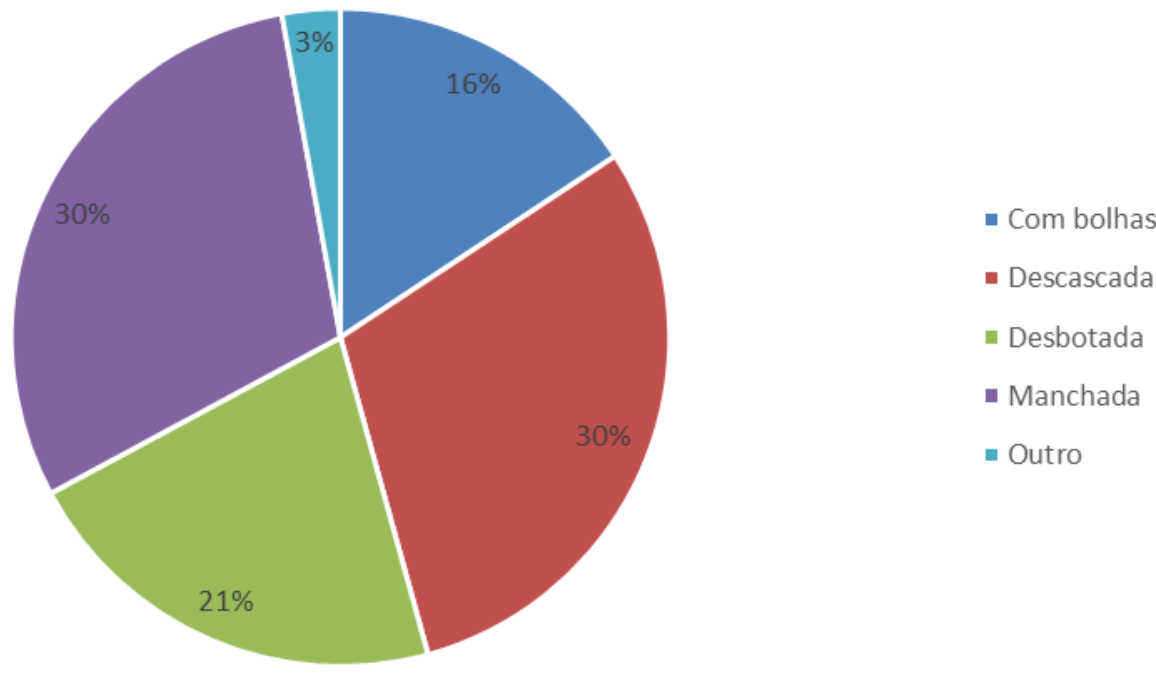

Figura 10: Distribuição das ocorrências em pintura

A figura 11 ilustra o descascamento da pintura em pontos de umidade e formação de bolor, problema recorrente nas unidades vistoriadas. 

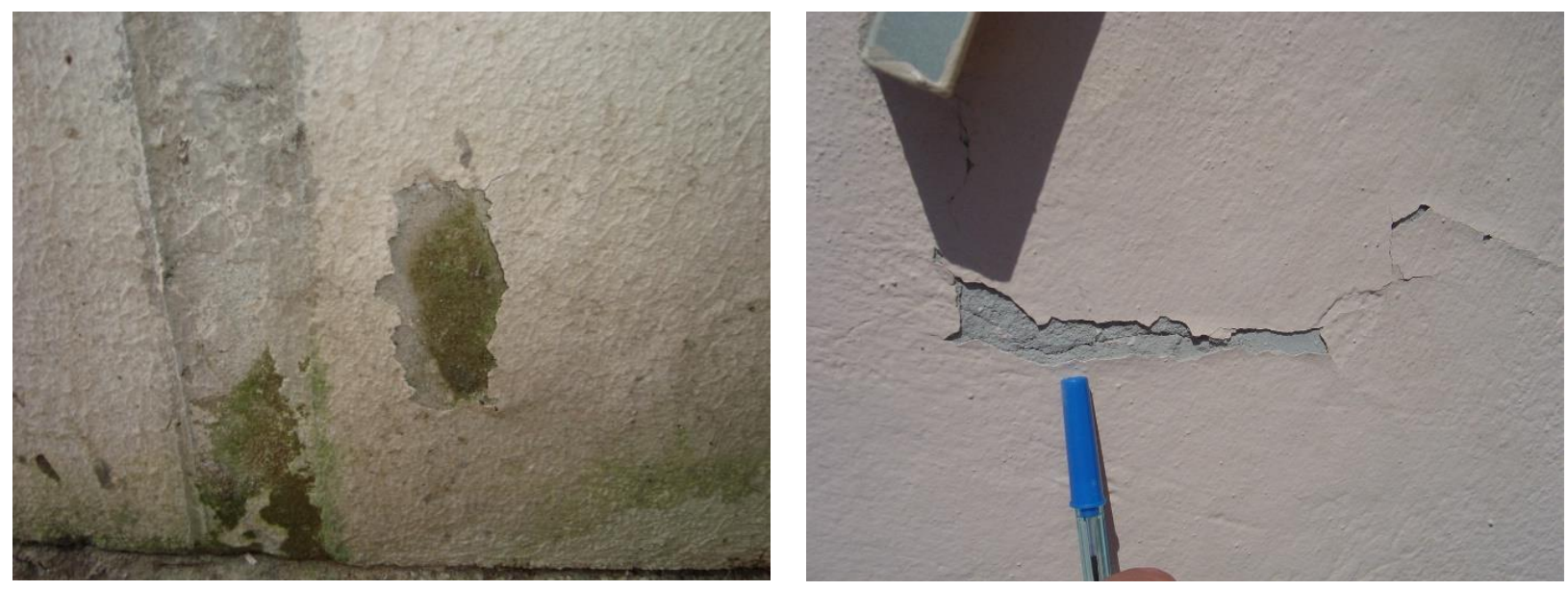

Figura 10: Destacamento da pintura e formação de bolor

\title{
4.5 Portas e Janelas
}

Como defeito de portas e janelas foram considerados pintura descascada, fechadura com problema, empenamento, emperramento e outros. No Loteamento Chapéu do Sol, em 58,33\% das unidades foram identificados problemas em portas e janelas, dos quais os mais frequentes foram fechadura com problema e empenamento, constantes, igualmente, em 41,67\% das unidades. Já no Residencial Nova Chocolatão, 55,56\% das unidades apontaram defeito neste elemento, sendo o defeito mais frequente pintura descascada, ocorrendo em 33,33\% das unidades. No Loteamento São Guilherme $47,37 \%$ das unidades manifestou defeito nas esquadrias.

Os apontamentos "outros" para defeitos nas portas e janelas nos Loteamentos Nova Chocolatão e São Guilherme, em sua maioria (7 das 10 ocorrências) são de corrosão na esquadria. Globalmente, 54,10\% das unidades vistoriadas apresentou problema nas esquadrias. Observa-se que o loteamento Chapéu do Sol representa 51,9\% das 81 ocorrências deste elemento. Como mostra o gráfico XX, a composição dos defeitos é homogênea, sendo os mais frequentes pintura descascada ( $24 \%$ das ocorrências) e fechadura com problema (22\% das ocorrências).

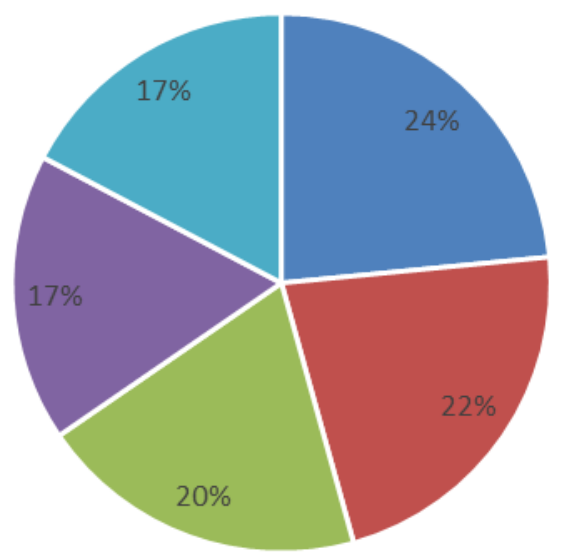

\author{
- Pintura descascada \\ - Fechadura com problema \\ - Empenadas \\ - Emperradas \\ - Outro
}

Figura 11: Distribuição das ocorrências em portas e janelas

No Loteamento Chapéu do Sol, verificou-se o lascamento na parte inferior das folhas das portas de madeira em algumas unidades visitadas.

\subsection{Coberturas}

Como defeito de cobertura foram considerados entrada de água, telhas quebradas, forro podre, forro com cupins e forro deformado. No Loteamento Chapéu do Sol, 58,33\% das unidades visitadas foi verificado defeito na cobertura, em 
$54,17 \%$ unidades deste loteamento percebeu-se a entrada de água pela cobertura. Enquanto no Residencial Nova Chocolatão, 44,44\% das unidades apontaram defeito neste elemento, sendo, também, o defeito mais frequente entrada de água (44,44\% das unidades). No Loteamento São Guilherme 10,53\% das unidades manifestou defeito na cobertura, e, novamente, entrada de água é o mais frequente, apontado em 10,53\% das unidades.

De maneira geral, 39,34\% das unidades vistoriadas manifestou defeitos na cobertura. Ressalta-se que $69 \%$ dos 58 casos foram identificados no Loteamento Chapéu do Sol. Como mostra a figura 151, 40\% dos defeitos na cobertura foram identificados como entrada de água.

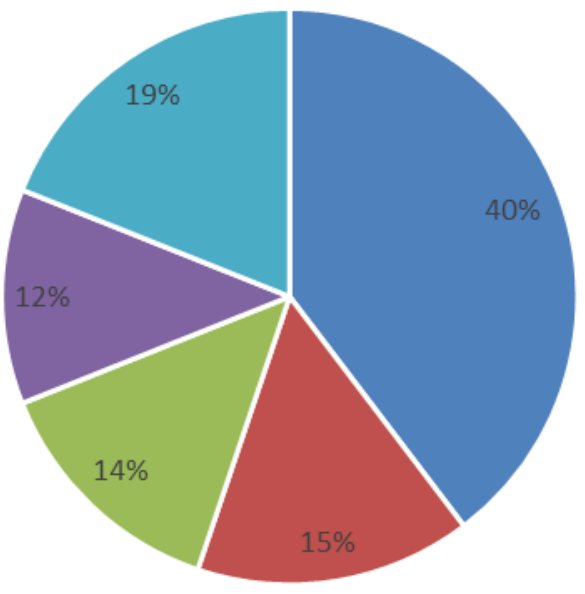

- Entra água

- Telhas quebradas

- Forro podre

- Forro com cupins

- Forro deformado

Figura 12: Distribuição das ocorrências em coberturas

É pertinente mencionar que no Loteamento Chapéu do Sol, as unidades foram entregues sem forro e algumas das unidades vistoriadas permaneciam sem a instalação no momento da vistoria elas ainda mostram o emprego de jornal para vedação da cobertura da unidade. A figura 13 ilustra o caso de unidades em que o telhado possui buracos, sendo motivo de insatisfação dos usuários, já que "chove" dentro das suas moradias.

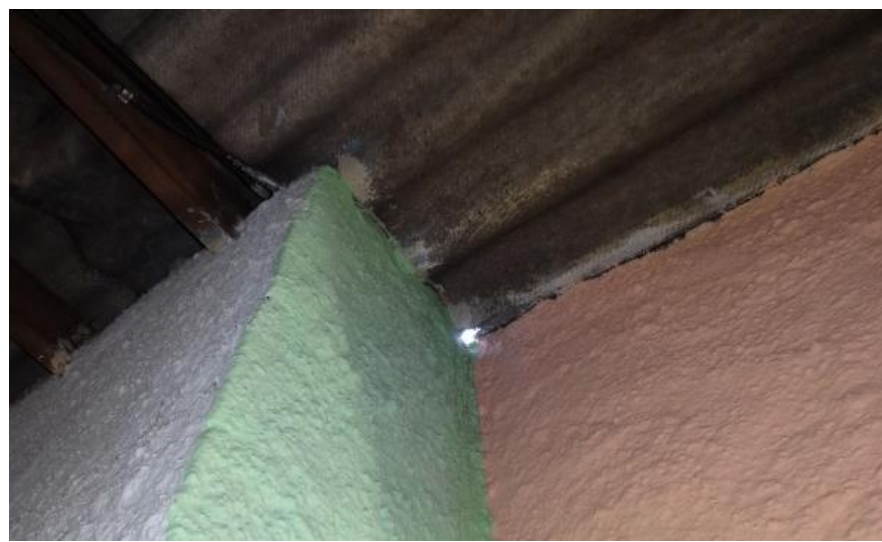

Figura 13: Cobertura sem forro e com buraco no telhado no Loteamento Chapéu do Sol

\subsection{Instalações Hidráulicas}

Como defeito de instalações hidráulicas foram considerados vazamentos, pouca pressão, canos quebrados e outros. No Loteamento Chapéu do Sol em 41,67\% das unidades visitadas foram verificados defeitos nas instalações hidráulicas, em 37,5\% das unidades havia canos quebrados e em 33,33\% vazamos. No Residencial Nova Chocolatão, 33,33\% das unidades apontaram defeito nas instalações hidráulicas, sendo os defeitos mais frequentes vazamento e canos quebrados, presentes em 11,11\% das unidades. No Loteamento São Guilherme houve apenas 2 ocorrências, 1 unidade com vazamento e 1 unidade com canos quebrados. ]

Do total das unidades visitadas, 29,51\% apresentou problema nas instalações hidráulicas, sendo que 78,10\% dos apontamentos ocorreram no Loteamento Chapéu do Sol. Como mostra a figura 159, 38\% dos defeitos nas paredes foram identificados como canos quebrados e $34 \%$ como vazamentos. Estes vazamentos dividem-se em vazamentos nas conexões de tubulações, devido à má colagem e em torneiras e registros, devido a falha na vedação. 


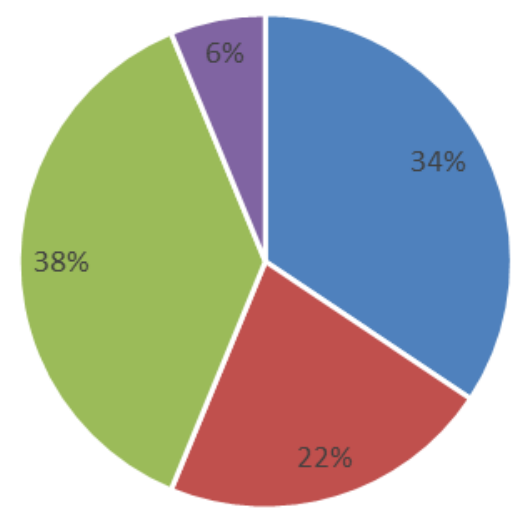

- Vazamentos

- Pouca pressão

- Canos quebrados

- Outro

Figura 13: Distribuição das ocorrências em Instalações Hidráulicas

\subsection{Instalações de Esgoto}

Como defeito de instalações de esgoto foram considerados vazamento, entupimento, mau cheiro e outros. No Loteamento Chapéu do Sol em 41,67\% das unidades visitadas foram registrados defeitos nas instalações de esgoto, em $33,33 \%$ verificou-se vazamentos, com relação direta a mau cheiro. No Residencial Nova Chocolatão, 16,67\% das unidades apresentou defeito neste elemento, em contrapartida no Loteamento São Guilherme, 15,79\% das unidades tinha problemas no esgoto, sendo mau cheiro o mais frequente $(15,79 \%)$.

Globalmente, 26,23\% das unidades vistoriadas apresentou problema nas instalações de esgoto. A figura 14 ilustra que $37 \%$ dos defeitos foram identificados como mau cheiro, que está diretamente relacionado aos demais, percebeu-se, ainda, que a maior parte dos entupimentos era motivada pela falta de manutenção periódica, por desconhecimento por parte do morador.

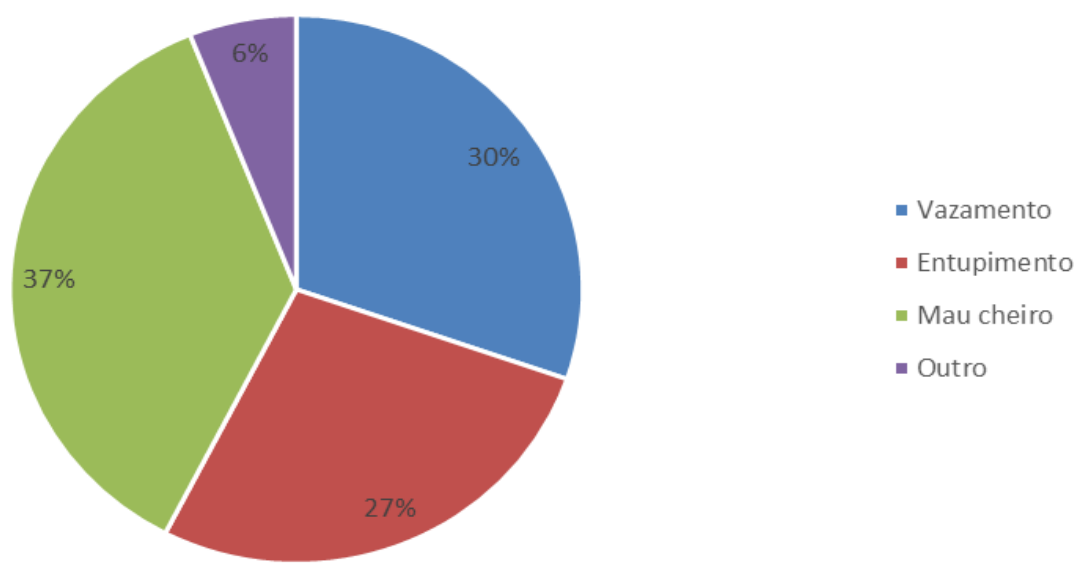

Figura 13: Distribuição das ocorrências em Instalações de Esgoto

Também chamou a atenção que na maioria das unidades foram realizadas instalações improvisadas, que por falta de conhecimento ou habilidade para execução, devido a fadiga, apresentavam vazamentos nas conexões.

\subsection{Instalações Elétricas}

Como defeito de instalações elétricas foram considerados, disjuntores caindo, curto circuito, não funcionamento de interruptores e tomadas e outros. No Loteamento Chapéu do Sol, 37,50\% das unidades visitadas foram registradas com defeito, já no Loteamento São Guilherme, 26,32\% das unidades apontaram defeito neste elemento, sendo o defeito mais frequente tomadas que não funcionavam (21,05\% das unidades). No Residencial Nova Chocolatão apenas 2 unidades apresentaram problemas elétricos, sendo 1 deles curto circuito. 
Do total de unidades vistoriadas, 24,59\% apresentou problemas elétricos, a maior parte das ocorrências (74,4\%) foram identificadas no loteamento Chapéu do Sol. Como as unidades deste loteamento foram entregues sem forro, é elevado o número de unidades com fiação totalmente exposta.

Conforme ilustrado na figura $14,28 \%$ das ocorrências em instalações elétricas é de tomadas que não funcionam, $23 \%$ de curto circuitos e $21 \%$ de disjuntores que desligam.

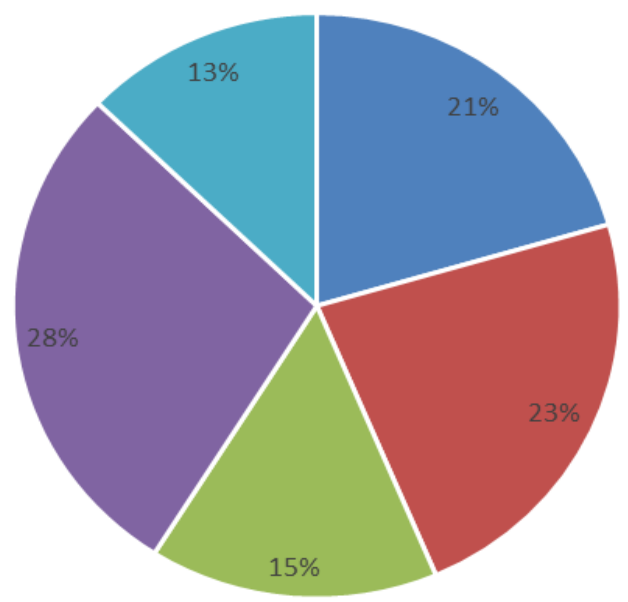

\author{
- Disjuntores desligam \\ - Curto circuito \\ - Interruptores não funcionam \\ - Tomadas não funcionam \\ - Outro
}

Figura 14: Distribuição das ocorrências em Instalações Elétricas

Os moradores executaram instalações elétricas para as modificações ambientais realizadas na edificação, a maior parte delas é irregular e está com a fiação exposta, como exemplificado e ilustrado pela figura 15, o que possivelmente motive os curtos circuitos, e por conseguinte a queda de disjuntores.
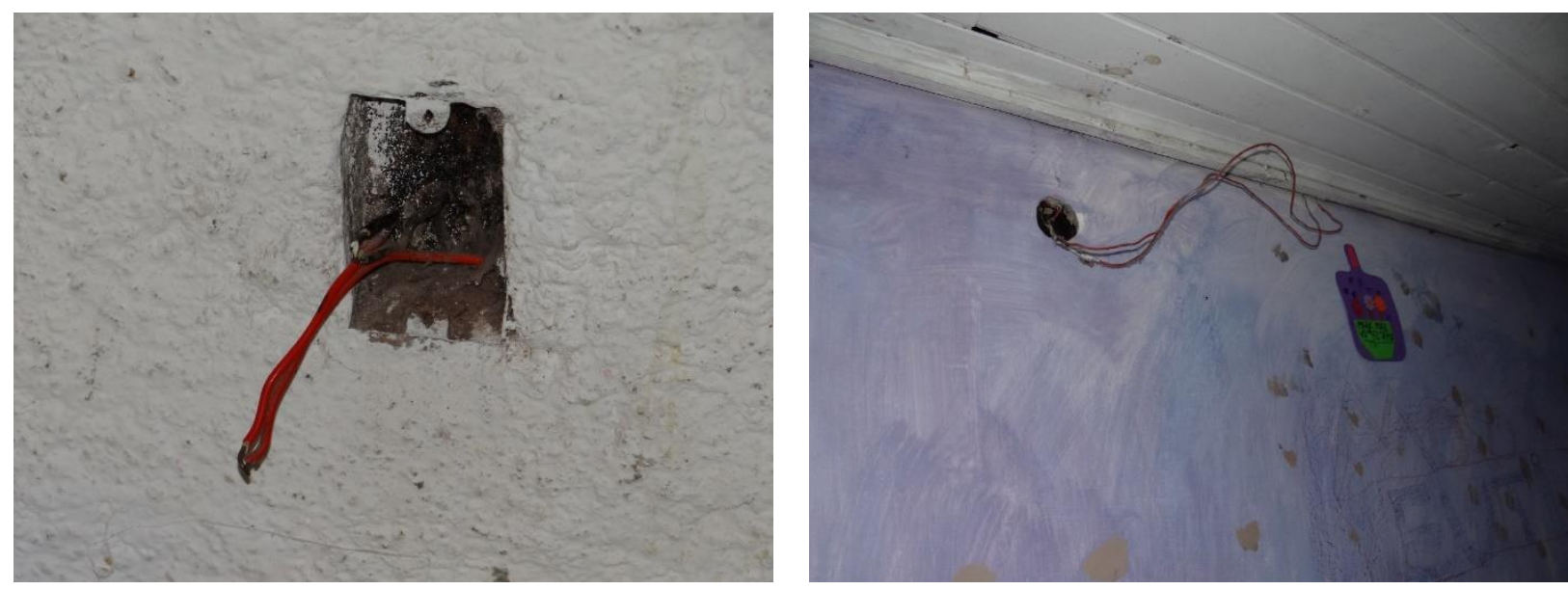

Figura 15: Fiações Expostas

\title{
5. CONCLUSÕES
}

Intervenções urbanas voltadas ao problema habitacional, engajadas na produção de habitações para a população de baixa renda, não são bem-sucedidas sem serem planejadas de modo a atender, primeiramente, às necessidades dos usuários. Carecem de projetos e do emprego de técnicas e tecnologias que permitam a redução de custo, sem afetar a qualidade, de forma que esta habitação supra todas as suas funções como qualquer outra habitação. Além de capacitar o usuário quanto à manutenção, potencializando sua vida-útil.

Frente ao disposto nos capítulos anteriores, infere-se que as técnicas de APO empregadas são adequadas para avaliação dos empreendimentos, qualificando o desempenho das habitações conforme seu uso, ressaltando-se o nível de satisfação dos usuários das HIS produzidas pelo DEMHAB. A avaliação complementou-se com o levantamento de manifestações patológicas mais recorrentes, portanto, os objetivos do trabalho foram atingidos. 
De acordo com a análise dos resultados, os entrevistados mostraram-se regularmente satisfeitos com as dimensões dos ambientes, destacando-se como menos satisfatório a cozinha e mais satisfatório a varanda, que foi construída pelos próprios usuários. A respeito do conforto ambiental, a principal insatisfação dos entrevistados é quanto a temperatura na habitação em dias quentes e frios.

A análise dos resultados mostra que os usuários estão insatisfeitos perante a qualidade da construção, principalmente quanto às janelas e portas. Com relação ao nível de satisfação dos usuários sobre as manifestações patológicas, portas e janelas novamente apontam como a principal insatisfação dos entrevistados, justificando a insatisfação com a qualidade delas.

Quanto a qualidade das instalações elétricas e hidráulicas, os resultados mostram um nível de satisfação médio "regular", relacionando-se ao fato de que aproximadamente metade dos entrevistados relatou ter tido problemas nas instalações, o que os induziu a reformar as instalações.

De maneira geral, em média, os entrevistados apresentaram nível de satisfação regular quanto à sua habitação. Estes resultados relacionam-se diretamente ao fato de $88,61 \%$ dos entrevistados já ter reformado ou deseja reformar sua moradia, destacando-se a ampliação de cômodos como a reforma mais desejada $(29,04 \%)$.

O levantamento de defeitos na habitação, validou os apontamentos dos usuários, já que 54,10\% das unidades visitadas apresentou defeitos em portas e janelas, representando 16,60\% das ocorrências. 11,27\% das ocorrências foram quanto a umidade em fundações, pisos e paredes, que condiz com a percepção dos entrevistados, que se declararam insatisfeitos quanto a umidade em suas moradias. Esta umidade pode ter relação com os vazamentos nas instalações hidráulicas e de esgoto mapeados, com a entrada de água pelo telhado e por impermeabilização deficiente nas fundações.

O relatório fotográfico evidenciou a falta de manutenção e limpeza da moradia, apontando a degradação de pinturas e revestimentos. Além de reformas inadequadas e instalações improvisadas, que, muitas vezes, trazem mais problemas ainda. Portanto, ressalta-se a importância do desenvolvimento de um manual de conservação e manutenção da habitação para os usuários das HIS, além do treinamento dos usuários.

\section{REFERÊNCIAS}

ABIKO, A. K. Introdução à Gestão Habitacional. São Paulo: EPUSP, 1995.

BONDUKI, N. Origens da habitação social no Brasil. Arquitetura moderna, lei do inquilinato e difusão da casa própria. $4^{\mathrm{a}}$ edição. ed. São Paulo: Estação Liberdade, 2004.

CARDOSO, A. L; KAPP, S. Marco Teórico da Rede Morar TS. RISCO - Revista de pesquisa em arquitetura e urbanismo do programa de pós-graduação do instituto de arquitetura e urbanismo iau-usp. São Paulo, 2013.

COSTA, M. A. O Estatuto da Cidade e a Habitat III: um balanço de quinze anos da política urbana no Brasil e a nova agenda urbana. Brasília: IPEA, 2016.

DEPARTAMENTO MUNICIPAL DE HABITAÇÃO-DEMHAB. Plano Municipal de Habitação de Interesse Social. Porto Alegre. 2009.

FRANÇA, A. J. G. L. Melhoria contínua aplicada a edificações de tipologia padronizada: a gestão do conhecimento no contexto do portfólio de ativos. São Paulo: FAUUSP, 2016.

MARICATO, E. Habitação social em áreas centrais. Oculum Ensaios - PUC, p. 2-12, 2000.

ORNSTEIN, S. W. Avaliação pós ocupação no Brasil, 30 anos: O que há de novo? PROJETAR, p. 7-12, 2017.

ORSTEIN, S.; BRUNA, G.; ROMÉRO, M. Ambiente Construído e Comportamento: a avaliação pós-ocupação e a qualidade ambiental. 1. ed. São Paulo: Studio Nobel, 1995.

RHEINGANTZ, P. A. Observando a qualidade do lugar: procedimentos para a avaliação pós-ocupação. Rio de Janeiro: Universidade Federal do Rio de Janeiro, Faculdade de Arquitetura e Urbanismo, Pós- Graduação em Arquitetura, 2009.

SANTOS, M. V. A. D. Desenvolvimento de Tipologias para habitações de interesse social. Fortaleza: Universidade Federal do Ceará, 2011. 